\title{
Porphyrin-anthraquinone dyads: Synthesis, spectroscopy and photochemistry
}

\author{
P PRASHANTH KUMAR*, G PREMALADHA and BHASKAR G MAIYA ${ }^{\dagger}$ \\ School of Chemistry, University of Hyderabad, Hyderabad 500 046, India \\ e-mail: ppk13d@yahoo.com
}

\begin{abstract}
Free-base $\left(\mathrm{H}_{2} \mathrm{~L}^{2}\right)$, copper(II) $\left(\mathrm{CuL}^{2}\right)$ and zinc(II) $\left(\mathrm{ZnL}^{2}\right)$ derivatives of a porphyrin-anthraquinone conjugate with an azomethine group separating the two photoactive subunits have been synthesized and characterized by mass (FAB), IR, UV-visible, ${ }^{1} \mathrm{H}$ NMR and ESR spectroscopic techniques and also by cyclic and differential pulse voltammetric methods. Analysis of the data reveals that the spectral and electrochemical properties of the individual chromophoric entities are retained and that there is no specific $\pi-$ $\pi$ interaction between the porphyrin and anthraquinone subunits. $\mathrm{H}_{2} \mathrm{~L}^{2}$ and $\mathrm{ZnL}^{2}$ are shown to exhibit substantial quenching (88-97\%) of the porphyrin fluorescence compared to their corresponding monomeric analogues. An intramolecular electron-transfer mechanism is proposed for the substantial decrease in fluorescence in both derivatives. The fluorescence decays of porphyrin-anthraquinone conjugates are fit to $2 / 3$ exponentials and indicate that multiple orientations of the porphyrin and anthraquinone groups contribute to the electron-transfer event. These results are in good agreement with steady-state fluorescence results. From the time-resolved fluorescence data, the electron-transfer rate constants are calculated, indicating $k_{\mathrm{ET}}$ values in the range of $1.1 \times 10^{9}$ to $9.9 \times 10^{10} \mathrm{~s}^{-1}$ that are dependent upon the solvent.
\end{abstract}

Keywords. Porphyrin-anthraquinone dyad; redox properties; electron transfer; time-resolved studies.

\section{Introduction}

Recently, there has been a great deal of research activity on the photochemical properties of porphyrincontaining donor-acceptor (D-A) molecular assemblies in an attempt to mimic the primary light-driven step in natural photosynthetic reaction centers. ${ }^{1-8}$ Covalently/non-covalently linked porphyrin-quinone molecules have been studied extensively as models for the light-initiated charge separation step in the photosynthesis. ${ }^{9-11}$ Many current investigations are concerned with porphyrin-quinone molecules in order to understand the role of factors like distance, orientation, energetics and medium in determining the rate of intramolecular photoinduced electron transfer (PET). ${ }^{12-21}$ The nature of the bridge linking the $\mathrm{D}$ and $\mathrm{A}$ components is also a subject of much interest since PET in many donor-acceptor (D-A) molecules is known to be dominated by through-bond interactions. ${ }^{3}$ As part of our continuing interest in studies of PET processes, we report here the design, synthesis, spectral (UV-visible, IR, FAB-MS, ${ }^{1} \mathrm{H}$ NMR and ESR) and electrochemical characterization

\footnotetext{
${ }^{\dagger}$ Deceased

*For correspondence
}

and, more importantly, the photophysical properties of an azomethine-bridged porphyrin-anthraquinone dyad $\left(\mathrm{H}_{2} \mathrm{~L}^{2}\right)$ and its copper(II) $\left(\mathrm{CuL}^{2}\right)$ and $\mathrm{zinc}(\mathrm{II})$ $\left(\mathrm{ZnL}^{2}\right)$ derivatives (figure 1).

\section{Experimental}

\subsection{General}

The chemicals and solvents utilized in this study were purchased from either the Aldrich Chemical Co (USA) or E Merck (India). Solvents utilized for spectroscopic and electrochemical experiments were further purified using standard procedures. ${ }^{22}$

\subsection{Synthesis}

2.2a $\mathrm{H}_{2} L^{1}$ : The precursor porphyrin 5-(4-aminophenyl)-10,15,20-tri(4-methylphenyl) porphyrin $\left(\mathrm{H}_{2} \mathrm{~L}^{1}\right)$ was synthesized by the literature method. ${ }^{23}$ ${ }^{1} \mathrm{H}$ NMR $\left(\mathrm{CDCl}_{3}, \delta\right.$ in ppm): $8.90\left(m, 8 \mathrm{H}_{\beta}\right), 8.10(d$, $\left.J=7.8 \mathrm{~Hz}, 6 \mathrm{H}_{o}\right), 8.01\left(d, J=8.6 \mathrm{~Hz}, 2 \mathrm{H}_{o^{\prime}}\right), 7.55(d$, $\left.J=7.8 \mathrm{~Hz}, 6 \mathrm{H}_{m}\right), 7.07\left(d, J=8.6 \mathrm{~Hz}, 2 \mathrm{H}_{m^{\prime}}\right), 4.03(s$, $\left.2 \mathrm{H}_{\text {amine }}\right), 2.71\left(s, 9 \mathrm{H}_{i}\right),-2.74\left(b s, 2 \mathrm{H}_{N H}\right)$; UV/Vis $\left[\lambda_{\max } / \mathrm{nm}(\log \varepsilon), \mathrm{CH}_{2} \mathrm{Cl}_{2}\right]: 650$ (3.65), 594 (3.62), 555 (3.94), 518 (4.12), 421 (5.44). 


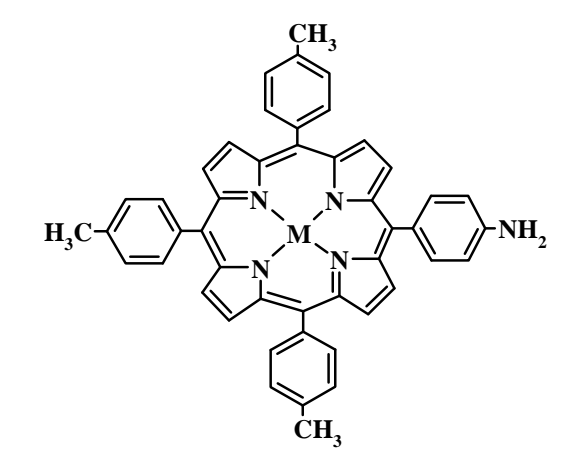

$\mathbf{M}=2 \mathrm{H}\left(\mathbf{H}_{2} \mathbf{L}^{1}\right), \mathrm{Gu}(\mathrm{II})\left(\mathbf{C u L}^{1}\right), \mathrm{Zn}(\mathrm{II})\left(\mathbf{Z n L}^{1}\right)$

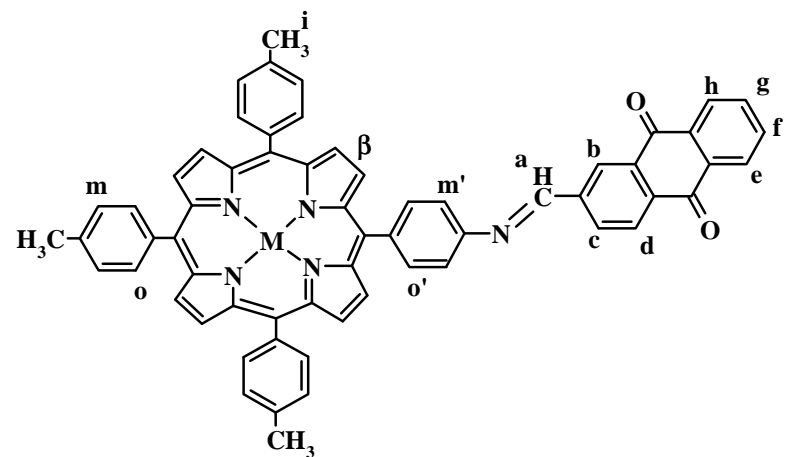

$\mathbf{M}=2 \mathrm{H}\left(\mathbf{H}_{2} \mathbf{L}^{2}\right), \mathrm{Gu}(\mathrm{II})\left(\mathbf{C u L}^{2}\right), \mathrm{Zn}(\mathrm{II})\left(\mathbf{Z n L}^{2}\right)$

(i) Toluene (dry), $4 \AA$ molecular sieves, 8-12 h, reflux, $\mathrm{N}_{2}$

Figure 1. Scheme leading to the synthesis of new 'porphyrin-anthraquinone' dyads investigated in this study.

2.2b CuL and $Z n L^{1}$ : Copper(II) and zinc(II) derivatives were prepared and purified according to reported procedures. ${ }^{24}$ Due to self-assembly, $\mathrm{ZnL}^{1}$ shows more ${ }^{1} \mathrm{H}$ NMR signals than the corresponding free-base porphyrin $\left(\mathrm{H}_{2} \mathrm{~L}^{1}\right)^{25} .{ }^{1} \mathrm{H}$ NMR $\left(\mathrm{CDCl}_{3}, \delta\right.$ in ppm), $\mathrm{ZnL}^{1}: 8.95\left(d d, J=4.8,3.6 \mathrm{~Hz}, 4 \mathrm{H}_{\beta}\right), 8.88(d$, $\left.J=4.8 \mathrm{~Hz}, 2 \mathrm{H}_{\beta}\right), 8.82\left(d, J=4.8 \mathrm{~Hz}, 2 \mathrm{H}_{\beta}\right), 8.13(d$, $\left.J=9.2 \mathrm{~Hz}, 2 \mathrm{H}_{o}\right), 8.07\left(d, J=7.2 \mathrm{~Hz}, 4 \mathrm{H}_{o}\right), 7.64(d$, $\left.J=8.4 \mathrm{~Hz}, 2 \mathrm{H}_{o^{\prime}}\right), 7.54\left(d, J=8.0 \mathrm{~Hz}, 2 \mathrm{H}_{m}\right), 7.46(d$, $\left.J=7 \cdot 2 \mathrm{~Hz}, 4 \mathrm{H}_{m}\right), 5 \cdot 77\left(b s, 2 \mathrm{H}_{m^{\prime}}\right), 2 \cdot 60-2 \cdot 75\left(m, 9 \mathrm{H}_{i}\right)$, $1.90\left(b s, 2 \mathrm{H}_{\text {amine }}\right) ; \mathrm{UV} / \mathrm{Vis}\left[\lambda_{\max } / \mathrm{nm}(\log \varepsilon), \mathrm{CH}_{2} \mathrm{Cl}_{2}\right]$, $\mathrm{CuL}^{1}$ : 578 (3.51), 541 (4.22), 506 (3.48), 418 (5.47) and $\mathrm{ZnL}^{1}: 590(3 \cdot 71), 550(4 \cdot 20), 422(5 \cdot 51)$.

2.2c AQ-2-CHO: Anthraquinone-2-carboxaldehyde was prepared and purified starting with 2-methylanthraquinone (2-MeAQ) by the standard procedure. ${ }^{26}$ ${ }^{1} \mathrm{H} \mathrm{NMR}\left(\mathrm{CDCl}_{3}, \delta\right.$ in ppm): $10 \cdot 24\left(s, 1 \mathrm{H}_{a}\right), 8 \cdot 80(s$, $\left.1 \mathrm{H}_{b}\right), 8.48\left(d, J=8.0 \mathrm{~Hz}, 1 \mathrm{H}_{c}\right), 8.32\left(m, 3 \mathrm{H}_{d+e+h}\right)$, $7.89\left(m, 2 \mathrm{H}_{f+g}\right) ; \mathrm{UV} / \mathrm{Vis}\left[\lambda_{\max } / \mathrm{nm}(\log \varepsilon), \mathrm{CH}_{2} \mathrm{Cl}_{2}\right]$, 2-MeAQ: 329 (3.87), 278 (4.39), 258 (4.84).

2.2d $\mathrm{H}_{2} \mathrm{~L}^{2}: \mathrm{H}_{2} \mathrm{~L}^{1}(50 \mathrm{mg}, 0.074 \mathrm{mmol})$ and AQ-2CHO (87 mg, $0.37 \mathrm{mmol}$ ) were dissolved in $40 \mathrm{ml}$ of dry toluene containing $4 \AA$ molecular sieves. The resulting solution was refluxed under nitrogen atmosphere for $8 \mathrm{~h}$. The solvent was removed and the crude product was dissolved in $\mathrm{CH}_{2} \mathrm{Cl}_{2}$ and filtered. Evaporation of the solvent gave a purple solid, which was recrystallized several times from $\mathrm{CH}_{2} \mathrm{Cl}_{2}$ $\mathrm{CH}_{3} \mathrm{OH}$ to give $\mathrm{H}_{2} \mathrm{~L}^{2}$ in pure form. Yield $=53 \mathrm{mg}$ (0.059 mmol, 80\%). FAB-MS $(\mathrm{m} / \mathrm{z})$ : Calcd. M $\left(\mathrm{C}_{62} \mathrm{H}_{43} \mathrm{O}_{2} \mathrm{~N}_{5}\right)=889$, obsd. $(\mathrm{M}+\mathrm{H})^{+}=890 ; \mathrm{IR}(\mathrm{KBr}$ pellet, $v$ in $\left.\mathrm{cm}^{-1}\right): 1591(\mathrm{C}=\mathrm{N}$ stretch $) ;{ }^{1} \mathrm{H}$ NMR $\left(\mathrm{CDCl}_{3}, \delta\right.$ in ppm): $8.99\left(s, 1 \mathrm{H}_{a}\right), 8.94-8.82(m$, $\left.9 \mathrm{H}_{\beta+b}\right), 8.56\left(d, J=8.0 \mathrm{~Hz}, 1 \mathrm{H}_{c}\right), 8.47(d, J=7.6 \mathrm{~Hz}$, $\left.1 \mathrm{H}_{d}\right), 8.36\left(m, 2 \mathrm{H}_{e+h}\right), 8.30\left(d, J=8.2 \mathrm{~Hz}, 2 \mathrm{H}_{o^{\prime}}\right)$, $8.11\left(d, J=7.6 \mathrm{~Hz}, 6 \mathrm{H}_{o}\right), 7.83\left(m, 2 \mathrm{H}_{f+g}\right), 7.69(d$, $\left.J=8.2 \mathrm{~Hz}, 2 \mathrm{H}_{m^{\prime}}\right), 7.57\left(d, J=7.6 \mathrm{~Hz}, 6 \mathrm{H}_{m}\right), 2.72(s$, $\left.9 \mathrm{H}_{i}\right),-2.76\left(\mathrm{bs}, 2 \mathrm{H}_{N H}\right)$; UV/Vis $\left[\lambda_{\max } / \mathrm{nm}(\log \varepsilon)\right.$, $\mathrm{CH}_{2} \mathrm{Cl}_{2}$ ]: 649 (3.70), 593 (3.70), 554 (4.02), 517 (4.22), 421 (5.59), 268 (4.53).

2.2e $C u L^{2}$ and $Z n L^{2}$ : These compounds were prepared, starting with $\mathrm{CuL}^{1}$ or $\mathrm{ZnL}^{1}(25 \mathrm{mg}$ $\sim 0.034 \mathrm{mmol}$ ) and AQ-2-CHO (40 mg, $0.17 \mathrm{mmol}$ ), in a manner analogous to that described above for $\mathrm{H}_{2} \mathrm{~L}^{2}$. Yields $=\mathrm{CuL}^{2}: 27 \mathrm{mg}(0.028 \mathrm{mmol}, 82 \%)$, $\mathrm{ZnL}^{2}: 25 \mathrm{mg}$ (0.026 mmol, 77\%). IR (KBr pellet, $v$ in $\left.\mathrm{cm}^{-1}\right)$ : 1589 and 1593 respectively $(\mathrm{C}=\mathrm{N}$ stretch). ${ }^{1} \mathrm{H}$ NMR $\left(\mathrm{CDCl}_{3}, \delta\right.$ in ppm), $\mathrm{ZnL}^{2}: 8.97\left(m, 8 \mathrm{H}_{\beta}\right)$, $8.88\left(s, 1 \mathrm{H}_{a}\right), 8.46\left(s, 1 \mathrm{H}_{b}\right), 8.42(d, J=8.0 \mathrm{~Hz}$, $\left.1 \mathrm{H}_{c}\right), 8.31\left(d, J=7.6 \mathrm{~Hz}, 2 \mathrm{H}_{o^{\prime}}\right), 8.24(d, J=8.0 \mathrm{~Hz}$, $\left.1 \mathrm{H}_{d}\right), 8 \cdot 17-8.05\left(m, 7 \mathrm{H}_{o+e}\right), 7.96(d, J=7.2 \mathrm{~Hz}$, $\left.1 \mathrm{H}_{h}\right), 7.74-7.63\left(m, 4 \mathrm{H}_{m^{\prime}+f+g}\right), 7.56(d, J=7.8 \mathrm{~Hz}$, $\left.6 \mathrm{H}_{m}\right), 2.72\left(s, 9 \mathrm{H}_{i}\right)$; UV/Vis $\left[\lambda_{\max } / \mathrm{nm}(\log \varepsilon)\right.$, $\mathrm{CH}_{2} \mathrm{Cl}_{2}$ ], $\mathrm{CuL}^{2}: 577$ (3.44), 541 (4.16), $498(3 \cdot 52)$, $418(5 \cdot 31), 260(4 \cdot 48)$ and $\mathrm{ZnL}^{2}: 589$ (3.68), 550 (4.21), $422(5 \cdot 56), 271(4 \cdot 53)$.

\subsection{Methods}

UV-visible spectra were recorded on a Shimadzu Model UV-3101PC UV/Vis spectrophotometer for $1 \times 10^{-6} \mathrm{M}$ (porphyrin Soret band) $-5 \times 10^{-5} \mathrm{M}(\mathrm{Q}-$ bands and anthraquinone bands) solutions. Steady- 
state fluorescence spectra were recorded using a Spex model Fluoromax-3 spectrofluorimeter for solutions of optical density $\sim 0.2$ at the wavelength of excitation $\left(\lambda_{\text {ex }}\right)$. Fluorescence quantum yields $(\phi)$ were estimated by integrating the fluorescence bands and by using either 5,10,15,20-tetraphenylporphyrin $\left(\mathrm{H}_{2} \mathrm{TPP}\right)$ ( $\phi=0.13$ in $\mathrm{CH}_{2} \mathrm{Cl}_{2}$ ), 5,10,15,20-tetraphenylporphyrinatozinc(II) ([ZnTPP]) $\left(\phi=0.036\right.$ in $\left.\mathrm{CH}_{2} \mathrm{Cl}_{2}\right)$ as standards. ${ }^{27,28}$ Refractive index corrections have been incorporated while reporting the fluorescence data in various solvents. Fluorescence lifetimes were measured by the time-correlated single photon counting (TCSPC) method, as described previously. ${ }^{29,30}$ Briefly, the samples were excited by 4 ps laser $(\mathrm{Nd} /$ YAG pumped rhodamine $6 \mathrm{G}$ dye laser) pulses at a repletion rate of $800 \mathrm{kHz}$. Fluorescence was detected at the magic angle $\left(54.7^{\circ}\right)$ with respect to polarization of the incident beam by a microchannel plate photomultiplier (MCP PMT, R2809). The count rate employed was typically $2 \times 10^{4} \mathrm{~s}^{-1}$. Excitation wavelength was fixed at $575 \mathrm{~nm}$ and fluorescence was collected at $650 \mathrm{~nm}$. Deconvolution of the data was carried out by the method of iterative reconvolution of the instrument response function and the assumed decay function. Goodness of fit of the experimental data to the assumed decay function was judged by standard statistical tests (i.e. random distribution of weighted residuals, autocorrelation function and values of reduced $\chi^{2}$ ). FAB mass spectra were recorded using a Jeol SX 102/DA-6000 mass spectrometer/data system. ${ }^{1} \mathrm{H}$ NMR spectra were recorded on a Bruker NR-400 AF-FT NMR spectrometer using $\mathrm{CDCl}_{3}$ as the solvent and tetramethylsilane (TMS) as an internal standard. ESR spectra for the copper(II) systems were run on a Jeol JES-FA200 X-band ESR spectrometer in toluene at $100 \pm 3 \mathrm{~K}$. Diphenyl picryl hydrazide (DPPH) was used as the $g$-marker. Cyclic and differential-pulse voltammetric experiments $\left(\mathrm{CH}_{2} \mathrm{Cl}_{2}, 0 \cdot 1 \mathrm{M}\right.$ tetrabutylammonium perchlorate, TBAP) were performed on a $\mathrm{CH}$ Instruments model CHI 620A electrochemical analyser as detailed in our previous studies (working- and auxiliary electrodes: Pt; reference electrode: $\mathrm{Ag}) .^{31-36} \mathrm{Fc}^{+} / F c$ $(F c=$ ferrocene $)$ couple was used to calibrate the redox potential values, which are reported in $V$ vs SCE $\left(E_{1 / 2}\left(F c^{+} / F c\right)=0.48 \mathrm{~V}\right.$ vs SCE in $\mathrm{CH}_{2} \mathrm{Cl}_{2}$, 0.1 M TBAP under our experimental conditions).

Care was taken to avoid the entry of direct, ambient light into the samples in all the spectroscopic and electrochemical experiments. Unless otherwise specified, all the experiments were carried out at $293 \pm 3 \mathrm{~K}$.

\section{Results and discussion}

\subsection{Design and synthesis}

Figure 1 depicts the scheme leading the synthesis of $\mathrm{H}_{2} \mathrm{~L}^{2}, \mathrm{CuL}^{2}$ and $\mathrm{ZnL}^{2}$. Syntheses of all the three new compounds have been accomplished here, in goodto-moderate yields, by simple Schiff base condensation between the amino porphyrin $\left(\mathrm{L}^{1}\right)$ derivatives and AQ-2-CHO.

\subsection{Ground state properties}

The mass (FAB) spectrum of $\mathrm{H}_{2} \mathrm{~L}^{2}$ shows a peak ascribable to the $(\mathrm{M}+\mathrm{H})^{+}$ion. ${ }^{1} \mathrm{H}$ NMR spectral data of $\mathrm{H}_{2} \mathrm{~L}^{2}$ and $\mathrm{ZnL}^{2}$ along with their individual constituents (i.e. $\mathrm{H}_{2} \mathrm{~L}^{1}, \mathrm{ZnL}^{1}$ and $\mathrm{AQ}-2-\mathrm{CHO}$ ) have been summarized in the experimental section and the spectra of $\mathrm{H}_{2} \mathrm{~L}^{2}$ and $\mathrm{ZnL}^{2}$ are shown in figure 2 . Comparison of these spectra with those of $\mathrm{H}_{2} \mathrm{~L}^{1} /$ $\mathrm{ZnL}^{1}$ and AQ-2-CHO reveals that the resonance positions of the various protons present either on the porphyrin macrocycle or the anthraquinone subunit are not shifted appreciably upon linking the two chromophores via the azomethine spacer. This is reasonable if one considers that the two aromatic rings are in 'trans' configuration with respect to the $\mathrm{C}=\mathrm{N}$ spacer, avoiding steric interaction. The structures of $\mathrm{H}_{2} \mathrm{~L}^{2}$ and $\mathrm{ZnL}^{2}$ derived from the molecular mechanics (PCM) calculations indeed suggest the same.

Interestingly, the anthraquinone peak positions in $\mathrm{ZnL}^{2}$ undergo a high field shift without appreciably perturbing the peak position of the porphyrin ring, figure 2. For example, resonances due to protons $b$, $d, e$ and $h$ (see figure 1) seen at 8.87, 8.47, 8.36 and $8.36 \mathrm{ppm}$ in $\mathrm{H}_{2} \mathrm{~L}^{2}$, appear shifted to $8 \cdot 46,8 \cdot 24,8 \cdot 11$ and $7.96 \mathrm{ppm}$ (identified by ${ }^{1} \mathrm{H}-{ }^{1} \mathrm{H}$ COSY experiment) respectively. Similarly, resonances due to the protons $a, c, f$ and $g$ are shifted upfield compared to the corresponding resonances in the spectrum of $\mathrm{H}_{2} \mathrm{~L}^{2}$. These changes could be interpreted in terms of ligation of the anthraquinone carbonyl group $(\mathrm{C}=\mathrm{O})$ with the central zinc(II) porphyrin. ${ }^{37,38}$ This would bring the protons present on the anthraquinone subunit into the shielding region of the ring current of the coordinated porphyrin. ${ }^{39}$

Maximum absorbance wavelengths $\left(\lambda_{\max }\right)$ and molar extinction coefficient $(\log \varepsilon)$ values of the three new dyads and of their constituent individual components (i.e. $\mathrm{H}_{2} \mathrm{~L}^{1}, \mathrm{CuL}^{1}, \mathrm{ZnL}^{1}$ and 2-MeAQ), as 


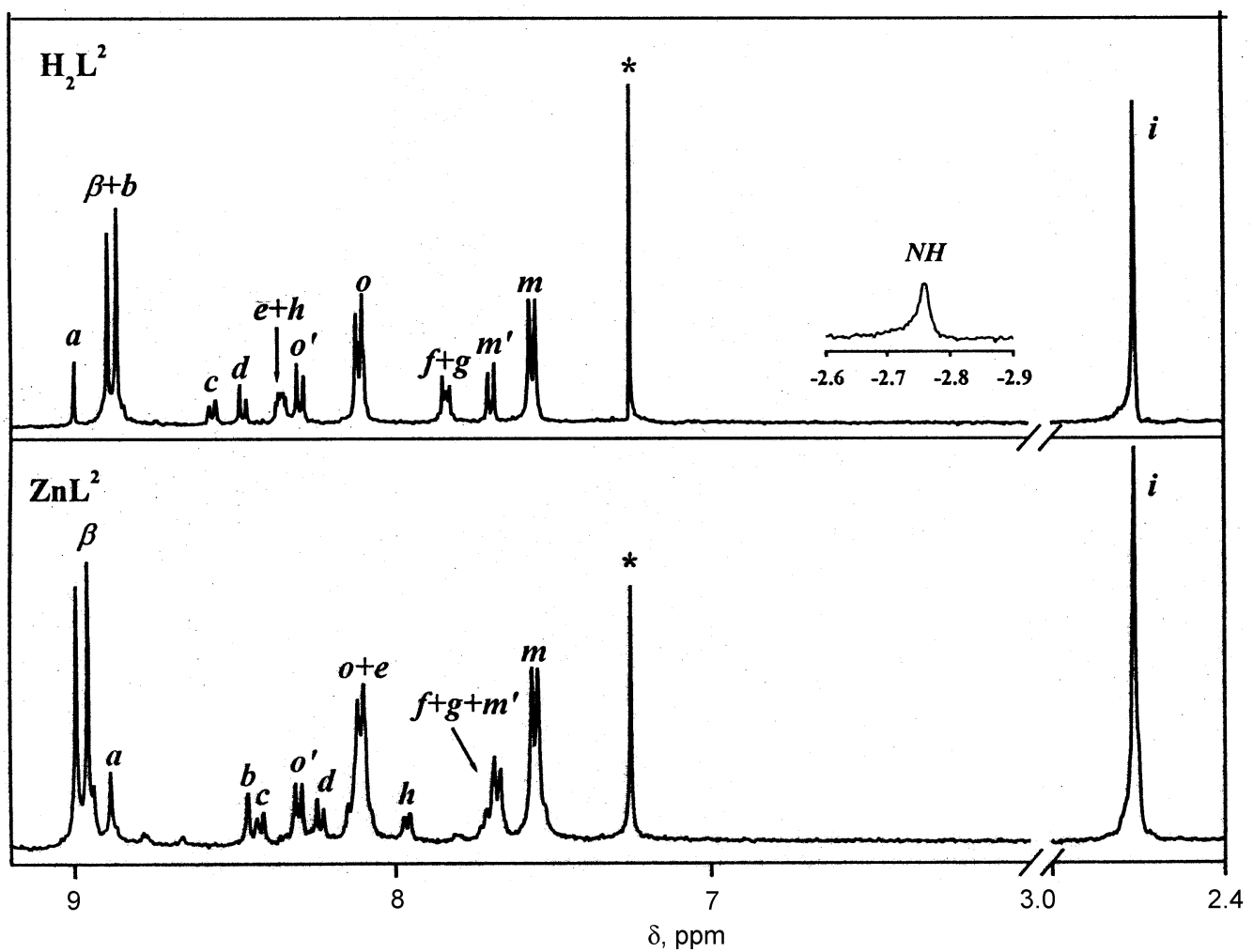

Figure 2. ${ }^{1} \mathrm{H}$ NMR spectra of $\mathrm{H}_{2} \mathrm{~L}^{2}$ and $\mathrm{ZnL}^{2}\left(\mathrm{CDCl}_{3}\right.$, TMS).

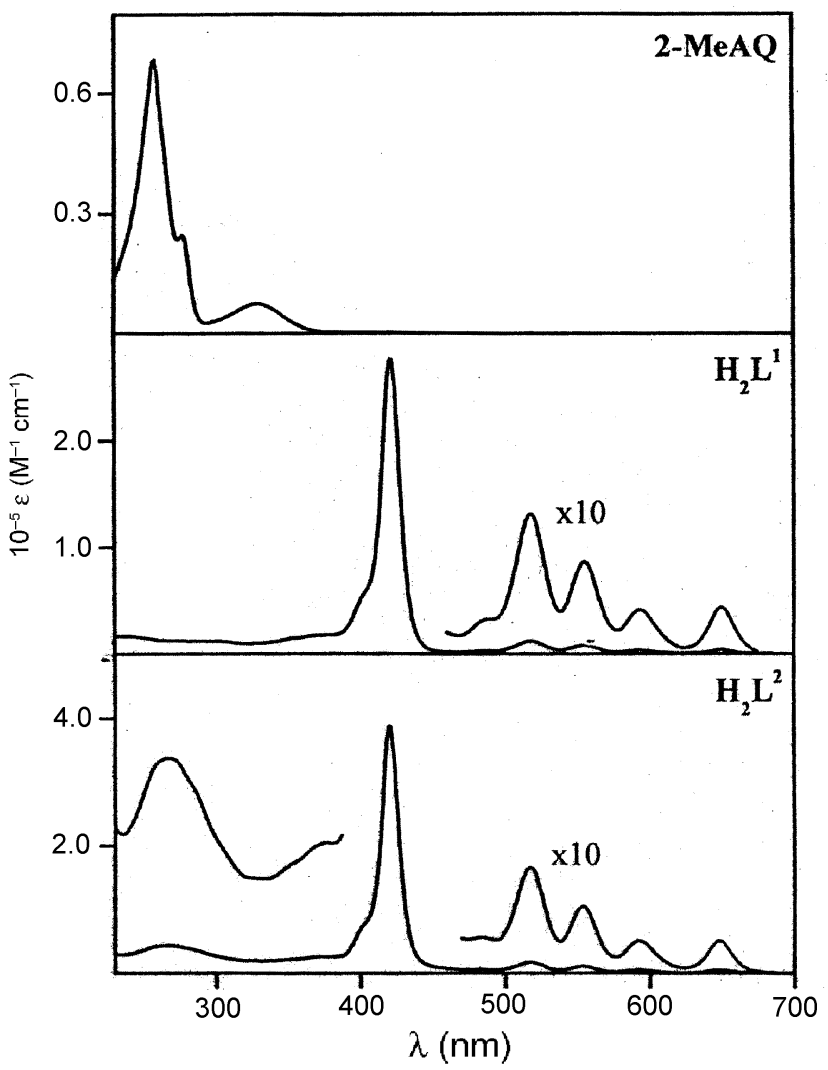

Figure 3. UV-visible spectra of $2-\mathrm{MeAQ}, \mathrm{H}_{2} \mathrm{~L}^{1}$ and $\mathrm{H}_{2} \mathrm{~L}^{2}$ in $\mathrm{CH}_{2} \mathrm{Cl}_{2}$. obtained from UV-visible studies, are summarised in $\S 2$. The UV-visible spectrum of $\mathrm{H}_{2} \mathrm{~L}^{2}$ is compared with the spectra of $\mathrm{H}_{2} \mathrm{~L}^{1}$ and 2-MeAQ in figure 3 . Comparison of these spectra and the data suggests that the appended anthraquinone chromophore in $\mathrm{H}_{2} \mathrm{~L}^{2}, \mathrm{CuL}^{2}$ and $\mathrm{ZnL}^{2}$ dominantly absorbs between $\approx 230$ and $330 \mathrm{~nm}$. On the other hand, porphyrin parts of $\mathrm{H}_{2} \mathrm{~L}^{2}, \mathrm{CuL}^{2}$ and $\mathrm{ZnL}^{2}$ show four/two Q-bands in the wavelength region $(500-700 \mathrm{~nm})$, where the anthraquinone part of each molecule does not absorb. Spectral data further reveal that both $\lambda_{\max }$ and $\log \varepsilon$ values of each dyad are within the same range as those of the constituent individual components.

Figure 4 illustrates the cyclic and differential pulse voltammograms of $\mathrm{H}_{2} \mathrm{~L}^{2}, \mathrm{CuL}^{2}$ and $\mathrm{ZnL}^{2}$. Table 1 summarises the redox potential data $\left(\mathrm{CH}_{2} \mathrm{Cl}_{2}, 0 \cdot 1 \mathrm{M}\right.$ TBAP) of the D-A systems investigated in this study along with that of the corresponding reference compounds. As per the data given in table 1, each new compound investigated shows up to three to four reduction peaks and two oxidation peaks under the experimental conditions employed in this study. Wave analysis suggests that while the first three reduction and two oxidation processes represent reversible $\left(i_{p c} / i_{p a}=0 \cdot 9-1 \cdot 0\right)$ and diffusion controlled $\left(i_{p c} /\right.$ $v^{1 / 2}=$ constant in the scan rate $(v)$ range 50 
Table 1. Redox potential data of $\mathrm{H}_{2} \mathrm{~L}^{2}, \mathrm{CuL}^{2}, \mathrm{ZnL}^{2}$ and their reference compounds, $\mathrm{CH}_{2} \mathrm{Cl}_{2}, 0 \cdot 1 \mathrm{M} \mathrm{TBAP}$.

\begin{tabular}{|c|c|c|c|}
\hline \multirow[b]{2}{*}{ Compound } & \multicolumn{2}{|c|}{ Potential ( $V$, vs SCE) } & \multirow[b]{2}{*}{$\Delta G\left({ }^{1} \mathrm{P} \rightarrow \mathrm{AQ}\right)(\mathrm{eV})$} \\
\hline & Oxidation & Reduction & \\
\hline 2-MeAQ & - & $-0 \cdot 92,-1 \cdot 37$ & - \\
\hline $\mathrm{H}_{2} \mathrm{TTP}^{\mathrm{b}}$ & $0 \cdot 88,1 \cdot 12$ & $-1 \cdot 23,-1 \cdot 57$ & - \\
\hline $\mathrm{CuTTP}^{\mathrm{b}}$ & $0.93,1.25$ & $-1 \cdot 30,-1 \cdot 72$ & - \\
\hline $\mathrm{ZnTTP}^{\mathrm{b}}$ & $0.79,1.08$ & $-1 \cdot 40,-1 \cdot 71$ & - \\
\hline $\mathrm{H}_{2} \mathrm{~L}^{2}$ & $0 \cdot 94,1 \cdot 16$ & $-0 \cdot 77,-1 \cdot 20,-1 \cdot 56$ & $-0 \cdot 19$ \\
\hline $\mathrm{CuL}^{2}$ & $0 \cdot 95,1 \cdot 23$ & $-0 \cdot 74,-1 \cdot 19,-1 \cdot 29,-1 \cdot 72$ & - \\
\hline $\mathrm{ZnL}^{2}$ & $0 \cdot 75,1 \cdot 05$ & $-0 \cdot 67,-1 \cdot 11,-1 \cdot 55,-1 \cdot 73$ & $-0 \cdot 67$ \\
\hline
\end{tabular}

${ }^{\mathrm{a}}$ Error limits: $E_{1 / 2}, \pm 0.03 \mathrm{~V} .{ }^{\mathrm{b}} \mathrm{H}_{2} \mathrm{~L}^{1}$ and its metal(II) derivatives gave ill-defined voltammograms. Hence, TTP derivatives are employed as reference compounds

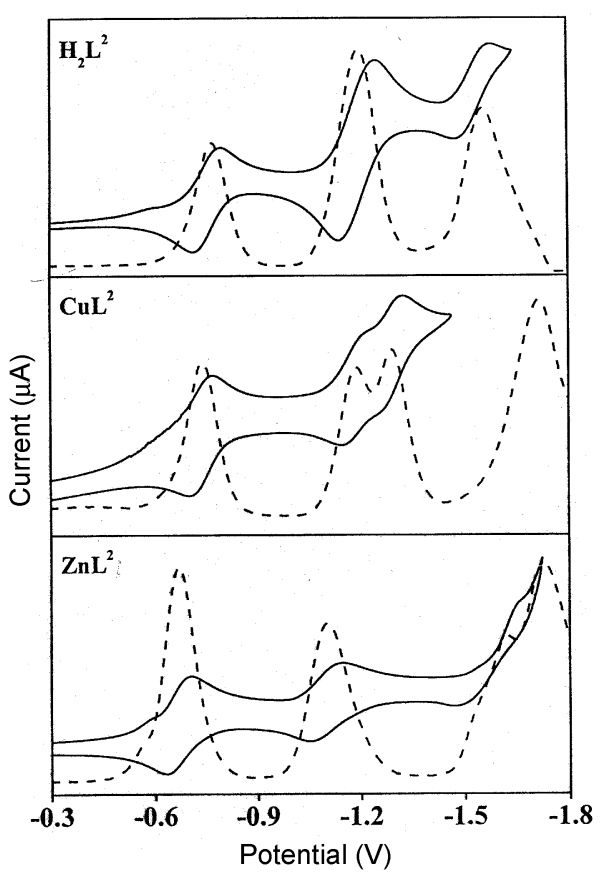

Figure 4. Cyclic and differential pulse voltammograms of $\mathrm{H}_{2} \mathrm{~L}^{2}, \mathrm{CuL}^{2}$ and $\mathrm{ZnL}^{2}$ in $\mathrm{CH}_{2} \mathrm{Cl}_{2}, 0 \cdot 1 \mathrm{M}$ TBAP (scan rate = $100 \mathrm{mV} \mathrm{s}^{-1}$ ).

$500 \mathrm{mV} / \mathrm{s})$ one-electron transfer $\left(\Delta E_{P}=60-70 \mathrm{mV}\right.$; $\Delta E_{P}=65 \pm 3 \mathrm{mV}$ for ferrocene ${ }^{+} /$ferrocene couple) $^{2}$ reactions and the remaining electrode process is either quasi-reversible $\left(i_{p c} / i_{p a}=0 \cdot 6-0 \cdot 8\right.$ and $\Delta E_{P}=80$ $150 \mathrm{mV}$ ) or irreversible under similar experimental conditions. The peaks occurring at anodic potentials are ascribed to successive one-electron oxidations of the porphyrin parts of $\mathrm{H}_{2} \mathrm{~L}^{2}, \mathrm{ZnL}^{2}$ and $\mathrm{CuL}^{2}$. As seen in figure 4, the differential voltammograms of $\mathrm{H}_{2} \mathrm{~L}^{2}$ in $\mathrm{CH}_{2} \mathrm{Cl}_{2}$ contain three reduction peaks corresponding to the reduction of the porphyrin/anthraquinone moiety. Comparing the reduction potentials of $\mathrm{H}_{2} \mathrm{~L}^{2}$ with its reference compounds 2-MeAQ and $\mathrm{H}_{2} \mathrm{TTP}$ (i.e. 5,10,15,20-tetra(4-methylphenyl)porphyrin), it was found that the reduction potentials for the first and third peaks are close to that for the first reduction of 2-MeAQ and second reduction of the porphyrin $\left(\mathrm{H}_{2} \mathrm{TTP}\right)$ ring respectively. The second reduction peak is more complex. Its peak current value is nearly twice that of the first or third peak. Since there is only one kind of substance in solution, the results indicate that two reductions (AQ moiety and porphyrin ring) of the molecular occur with one electron each and at the same potential. ${ }^{40}$ This analysis, which is based on comparison of the voltammograms of the dyads and the reference compounds, reveals that the redox potentials of the two subunits in the dyads are essentially close to the corresponding reference compounds.

In addition, the spin Hamiltonian parameters derived from the ESR spectrum of $\mathrm{CuL}^{2}$ (toluene, $100 \pm$ $3 \mathrm{~K}$ ) are also quite close to those of $\mathrm{CuL}^{1}$ or $\mathrm{CuTPP}^{41}\left(g_{\|}, g_{\perp}\right.$ and $A_{\|}^{\mathrm{Cu}}, A_{\perp}^{\mathrm{Cu}}, A_{\|}^{\mathrm{N}}$ and $A_{\perp}^{\mathrm{N}}$ $\left(\times 10^{4} \mathrm{~cm}^{-1}\right)$ values in that order are: $\mathrm{CuL}^{2}: 2 \cdot 176$, 2.035, 204, 33.0, 14.6 and 16.5; $\mathrm{CuL}^{1}: 2 \cdot 160,2 \cdot 028$, $202,33 \cdot 0,14 \cdot 2$ and $16 \cdot 5)$.

The spectroscopic and electrochemical features described above suggest that electronic communication between the porphyrin and anthraquinone chromophores is quite weak in these new conjugates.

\subsection{Singlet state properties}

$\mathrm{CuL}^{2}$ is found to be totally non-emissive, probably due to the paramagnetic nature of this complex. Steady-state fluorescence spectra of $\mathrm{H}_{2} \mathrm{~L}^{2}$ and $\mathrm{ZnL}^{2}$ measured in cyclohexane and $\mathrm{CH}_{2} \mathrm{Cl}_{2}$, compared 
Table 2. Fluorescence data of $\mathrm{H}_{2} \mathrm{~L}^{2}, \mathrm{ZnL}^{2}$ and their monomeric analogues in various solvents $\left(\lambda_{\mathrm{ex}}=550 \mathrm{~nm}\right)^{\mathrm{a}}$.

\begin{tabular}{llllll}
\hline & \multicolumn{4}{c}{$\lambda_{\text {em }}(\phi, \% \mathrm{Q})$} \\
\cline { 2 - 6 } Compound & \multicolumn{1}{c}{ Cyclohexane } & \multicolumn{1}{c}{ Toluene } & \multicolumn{1}{c}{$\mathrm{CH}_{2} \mathrm{Cl}_{2}$} & \multicolumn{1}{c}{$\mathrm{CH}_{3} \mathrm{CN}$} & \multicolumn{1}{c}{$\mathrm{CH}_{3} \mathrm{OH}$} \\
\hline $\mathrm{H}_{2} \mathrm{~L}^{1}$ & $657,723(0 \cdot 13)$ & $659,724(0 \cdot 186)$ & $658,722(0 \cdot 17)$ & $659,723(0 \cdot 25)$ & $659,721(0 \cdot 13)$ \\
$\mathrm{ZnL}^{1}$ & $598,644(0 \cdot 035)$ & $603,651(0 \cdot 054)$ & $601,649(0 \cdot 045)$ & $612,662(0 \cdot 032)$ & $611,661(0 \cdot 041)$ \\
$\mathrm{H}_{2} \mathrm{~L}^{2}$ & $655,721(0 \cdot 14,0)$ & $655,721(0 \cdot 192,0)$ & $656,720(0 \cdot 02,88)$ & $654,719(0 \cdot 016,94)$ & $655,719(0 \cdot 01,92)$ \\
$\mathrm{ZnL}^{2}$ & $598,642(0 \cdot 038,0)$ & $603,650(0 \cdot 061,0)$ & $602,650(0 \cdot 002,95)$ & $612,662(0 \cdot 0015,96)$ & $610,660(0 \cdot 0014,97)$ \\
\hline
\end{tabular}

${ }^{\mathrm{a}}$ Error limits: $\lambda, \pm 1 \mathrm{~nm} ; \phi, \pm 10 \%$

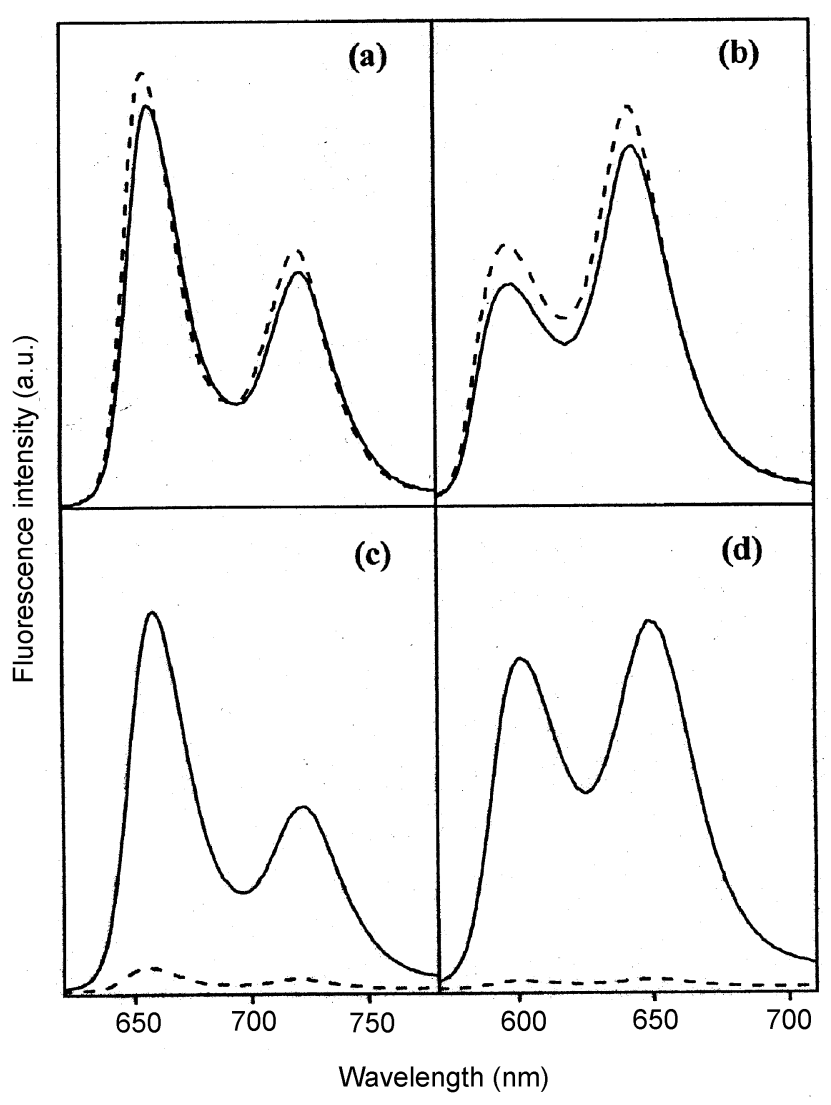

Figure 5. Fluorescence spectra $\left(\mathrm{OD} \approx 0.2\right.$ at $\lambda_{\mathrm{ex}}=$ $550 \mathrm{~nm})$ of $\left(\right.$ a) $\mathrm{H}_{2} \mathrm{~L}^{1}(-), \mathrm{H}_{2} \mathrm{~L}^{2}(\cdots \cdots \cdots)$ in cyclohexane; (b) $\mathrm{ZnL}^{1}(-), \mathrm{ZnL}^{2}(\cdots \cdots \cdots)$ in cyclohexane; (c) $\mathrm{H}_{2} \mathrm{~L}^{1}(-), \mathrm{H}_{2} \mathrm{~L}^{2}(\cdots \cdots \cdots)$ in $\mathrm{CH}_{2} \mathrm{Cl}_{2}$ and (d) $\mathrm{ZnL}^{1}$ $(\longrightarrow), \mathrm{ZnL}^{2}(\cdots \cdots \cdots)$ in $\mathrm{CH}_{2} \mathrm{Cl}_{2}$.

with the spectra of the corresponding individual $\left(\mathrm{H}_{2} \mathrm{~L}^{1} / \mathrm{ZnL}^{1}\right)$ components constituting them, are illustrated in figure 5. Analogous spectra are obtained in toluene, $\mathrm{CH}_{3} \mathrm{CN}$ and $\mathrm{CH}_{3} \mathrm{OH}$. Spectral shapes and wavelengths of maximum emission $\left(\lambda_{\text {em }}\right)$ of these D-A systems, when they are irradiated at the porphyrin absorption band $\left(\lambda_{\mathrm{ex}}=550 \mathrm{~nm}\right)$, are seen to be similar to the spectrum of either $\mathrm{H}_{2} \mathrm{~L}^{1}$ or $\mathrm{ZnL}^{1}$.

Fluorescence quantum yield $(\phi)$ for excitation in the porphyrin part of each dyad is similar to that of the unlinked porphyrin in cyclohexane and toluene, whereas it is strongly quenched in $\mathrm{CH}_{2} \mathrm{Cl}_{2}, \mathrm{CH}_{3} \mathrm{CN}$ and $\mathrm{CH}_{3} \mathrm{OH}$. The quenching efficiency values $(Q)$ calculated for these systems in different solvents, by using the equation below summarised in table 2 .

$$
Q=\frac{\phi\left(\mathrm{H}_{2} \mathrm{~L}^{1} / \mathrm{ZnL}^{1}\right)-\phi\left(\mathrm{H}_{2} \mathrm{~L}^{2} / \mathrm{ZnL}^{2}\right)}{\phi\left(\mathrm{H}_{2} \mathrm{~L}^{1} / \mathrm{ZnL}^{1}\right)},
$$

where $\phi\left(\mathrm{H}_{2} \mathrm{~L}^{1} / \mathrm{ZnL}^{1}\right)$ and $\phi\left(\mathrm{H}_{2} \mathrm{~L}^{2} / \mathrm{ZnL}^{2}\right)$ refer to the fluorescence quantum yields for $\mathrm{H}_{2} \mathrm{~L}^{1} / \mathrm{ZnL}^{1}$ and the $\mathrm{D}-\mathrm{A}$ systems $\mathrm{H}_{2} \mathrm{~L}^{2} / \mathrm{ZnL}^{2}$ respectively. These values are $88-97 \%$ for both $\mathrm{H}_{2} \mathrm{~L}^{2}$ and $\mathrm{ZnL}^{2}$. Time-resolved fluorescence data also suggest the same as described below.

Figure 6 and table 3 show that the fluorescence lifetimes, $\tau,\left(\lambda_{\mathrm{ex}}=575 \mathrm{~nm}\right.$ and $\left.\lambda_{\mathrm{em}}=650 \mathrm{~nm}\right)$ of both $\mathrm{H}_{2} \mathrm{~L}^{2}$ and $\mathrm{ZnL}^{2}$ remain quite similar to those of $\mathrm{H}_{2}$ TTP and ZnTTP in cyclohexane and toluene, but in $\mathrm{CH}_{2} \mathrm{Cl}_{2}, \mathrm{CH}_{3} \mathrm{CN}$ and $\mathrm{CH}_{3} \mathrm{OH}$ they are considerably shorter. In the case of $\mathrm{H}_{2} \mathrm{~L}^{2}$, we were able to fit these decays to a bi-exponential expression with a shorter lifetime and a longer lifetime. The shorter lifetime component of the bi-exponential decay is attributed to the deactivation (quenching) of the porphyrinexcited state by anthraquinone and the longer lifetime component is assigned either to the unquenched decay or decay of the porphyrin-hydroquinone generated by porphyrin sensitized photoreduction. ${ }^{42}$ However, the $\mathrm{ZnL}^{2}$ decay fits a three-exponential expression composed of one major (see table 3, shorter lifetime) component and two minor components (shorter and longer lifetime). From these data, the shorter lifetime with higher amplitude and longer lifetime components have the same origin as in $\mathrm{H}_{2} \mathrm{~L}^{2}$, but the additional shorter lifetime component may be explained in the following manner. The ${ }^{1} \mathrm{H}$ NMR data of $\mathrm{ZnL}^{2}$ suggest that there is a significant degree of complexation to the zinc(II) porphyrin core by the anthraquinone groups. We believe the anthraqui- 
Table 3. Fluorescence lifetime $(\tau, \mathrm{ns})$ data and electron transfer rate constants $\left(k_{\mathrm{ET}}, \mathrm{s}^{-1}\right)$ of $\mathrm{H}_{2} \mathrm{~L}^{2}$ and $\mathrm{ZnL}^{2 \mathrm{a}}$.

\begin{tabular}{lcccccccc}
\hline & \multicolumn{7}{c}{$\left(\tau, \mathrm{ns}(A \%){ }^{\mathrm{b}} k_{\mathrm{ET}}, \mathrm{s}^{-1}\right)$} \\
\cline { 2 - 8 } Compound & Cyclohexane & $\chi^{2}$ & $\mathrm{CH}_{2} \mathrm{Cl}_{2}$ & $\chi^{2}$ & $\mathrm{CH}_{3} \mathrm{CN}$ & $\chi^{2}$ & $\mathrm{CH}_{3} \mathrm{OH}$ & $\chi^{2}$ \\
\hline $\mathrm{H}_{2}$ TTP & 9.08 & 0.98 & 7.97 & 1.10 & 8.79 & 0.99 & 8.48 & 1.05 \\
$\mathrm{ZnTTP}$ & 1.89 & 1.07 & 1.61 & 1.07 & 1.71 & 1.20 & 1.69 & 1.21 \\
$\mathrm{H}_{2} \mathrm{~L}^{2}$ & 9.24 & 1.02 & $0.79(94)$ & 1.03 & $0.41(95)$ & 1.03 & $0.42(95)$ & 1.02 \\
& & & $6.68(6)$ & & $5.79(5)$ & & $6 \cdot 02(5)$ & $2.3 \times 10^{9}$ \\
$\mathrm{ZnL}^{2}$ & 1.78 & 0.99 & $0.03(91)$ & $1.26^{c}$ & $0.01(93)$ & $1.24^{\mathrm{c}}$ & $0.01(86)$ & $1.43^{\mathrm{c}}$ \\
& & & $0.71(1)$ & & $1.26(6)$ & & $0.71(6)$ & $1.86(8)$ \\
& & & $1.68(8)$ & & $2.61(1)$ & & $9.9 \times 10^{10}$ \\
\hline
\end{tabular}

${ }^{\mathrm{a}}$ Error limits: $\tau$ and $k_{\mathrm{ET}}, \pm 10 \%$. ${ }^{\mathrm{b}} A$ is the relative amplitude of the decay component. ${ }^{\mathrm{c}}$ In these cases, a two-exponential fit gave a better $\chi^{2}$ value, but the lifetime of one of the components was insignificant

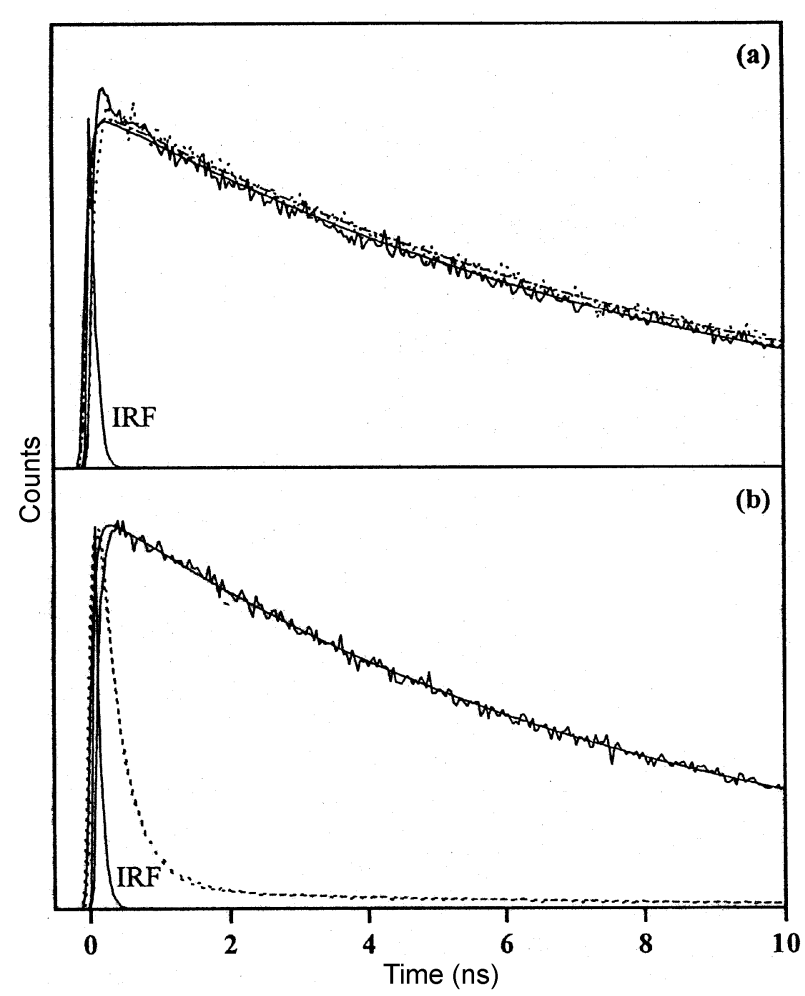

Figure 6. Time-resolved fluorescence decay profiles at $\lambda_{\text {ex }}=575 \mathrm{~nm}$ (a) $\mathrm{H}_{2} \mathrm{TTP}(-)$ and $\mathrm{H}_{2} \mathrm{~L}^{2}(\cdots \cdots \cdots)$ in cyclohexane (b) $\mathrm{H}_{2}$ TTP (-) and $\mathrm{H}_{2} \mathrm{~L}^{2}$ (…....) in $\mathrm{CH}_{2} \mathrm{Cl}_{2}$.

none-ligated state is responsible for the additional short-lived component obtained from the TCSPC experiments. ${ }^{12,13}$ The data in table 3 show that the shorter lifetimes observed for $\mathrm{H}_{2} \mathrm{~L}^{2}$ in all solvents (expect cyclohexane) have much larger amplitude relative to that observed for the longer lifetime components. Similar features are seen in the $\mathrm{ZnL}^{2}$ derivative.
We conclude, based on the steady state and timeresolved fluorescence data, that quenching of the porphyrin components in these dyads is predominantly due to the photoinduced electron transfer (PET) from the porphyrin singlet state to the anthraquinone subunit. As the static dielectric constant of the solvent is increased, the fluorescence quantum yield and lifetimes decrease gradually (see tables 2 and 3), which strongly suggest that an electrontransfer mechanism is involved. ${ }^{19}$ The free energy change for this PET, $\Delta G\left({ }^{1} \mathrm{P} \rightarrow \mathrm{AQ}\right)$, has been estimated using (2) below, and is summarised in table 1 ,

$$
\Delta G\left({ }^{1} \mathrm{P} \rightarrow \mathrm{AQ}\right)=E_{\mathrm{CT}}\left(\mathrm{P}^{+} \mathrm{AQ}^{-}\right)-E_{0-0}(\mathrm{P}) .
$$

Here $\mathrm{P}$ and AQ represent porphyrin and anthraquinone respectively. The $\Delta G\left({ }^{1} \mathrm{P} \rightarrow \mathrm{AQ}\right)$ values are estimated using the $E_{\mathrm{CT}}\left(\mathrm{P}^{+} \mathrm{AQ}^{-}\right)$[i.e. $E_{1 / 2}{ }^{o x}(\mathrm{P})-$ $\left.E_{1 / 2}{ }^{\text {red }}(\mathrm{AQ})\right]$ and singlet state energy (i.e. $E_{0-0}$ for $\mathrm{H}_{2} \mathrm{~L}^{2}=1.90 \mathrm{eV}$ and $\mathrm{ZnL}^{2}=2.09 \mathrm{eV}$ ). The more efficient quenching of the $\mathrm{ZnL}^{2}$ dyad excited state relative to that of the $\mathrm{H}_{2} \mathrm{~L}^{2}$ can be directly attributed to the significantly more exothermic value of $\Delta G_{P E T}$ for $\mathrm{ZnL}^{2}$. The absence of charge-transfer bands in any of the fluorescence spectra is an indication that no electronic interactions exist in the ground state between the porphyrin and anthraquinone. The rate constant $\left(k_{\mathrm{ET}}\right)$ for the $\mathrm{P}^{+} \mathrm{AQ}^{-}$are calculated using (3) and are summarised in table 3,

$$
k_{\mathrm{ET}}=\left(1 / \tau_{f}\right)-k
$$

where $k$ is the reciprocal of the lifetime of the $\mathrm{H}_{2} \mathrm{TTP} / \mathrm{ZnTTP}, \tau_{f}$ is the lifetime of $\mathrm{H}_{2} \mathrm{~L}^{2} / \mathrm{ZnL}^{2}$. The solvent-dependent $k_{\mathrm{ET}}$ values are in the range 


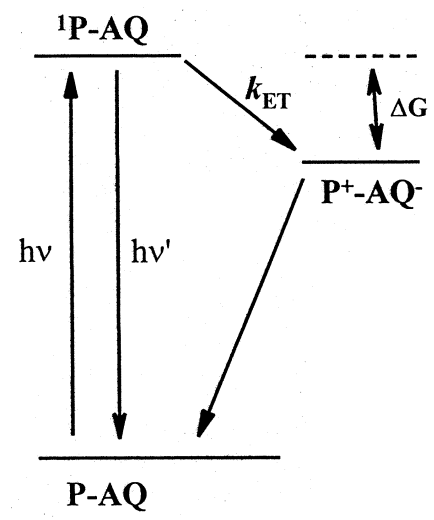

Figure 7. PET mechanism in $\mathrm{H}_{2} \mathrm{~L}^{2}$ and $\mathrm{ZnL}^{2}$ dyads. Here $\mathrm{P}, \mathrm{AQ}, h v$ and $h v^{\prime}$ refer to porphyrin, anthraquinone, absorbance and fluorescence respectively.

$1.1 \times 10^{9}$ to $9.9 \times 10^{10} \mathrm{~s}^{-1}$. The observed general increase of the $k_{\mathrm{ET}}$ values with increasing polarity of the solvent is consistent with the participation of a charge transfer state in the excited state deactivation of the porphyrin components of these systems. Figure 7 shows the energy levels of the porphyrin singletexcited state and the charge transfer state that participate in the PET processes in porphyrin-anthraquinone dyads.

\section{Conclusions}

In summary, new azomethine bridged $\mathrm{H}_{2} \mathrm{~L}^{2}$ and $\mathrm{ZnL}^{2}$ dyads have been synthesized and investigated by spectroscopic and electrochemical methods. These experiments reveal that there are no $\pi-\pi$ interactions between the porphyrin and anthraquinone moiety. Steady-state and time-resolved fluorescence spectroscopy indicates that $\mathrm{H}_{2} \mathrm{~L}^{2}$ and $\mathrm{ZnL}^{2}$ undergo rapid intramolecular electron transfer from porphyrin to anthraquinone. It is also possible that the bridging azomethine group may have a role to play in the efficient PET observed in the present set of 'porphyrin-anthraquinone' dyads, but it is not apparent from the results obtained in this study. Studies addressing this issue are currently in progress.

\section{Acknowledgement}

Financial support for this work from the Board of Research in Nuclear Sciences, Mumbai is gratefully acknowledged. We thank Prof M V Rajasekharan for help in preparation of this manuscript. We would also like to thank Prof N Periasamy and A S R Koti (TIFR, Mumbai, India) for the TCSPC measurements.
PPK and GP thank University Grants Commission and Council of Scientific and Industrial Research, respectively for fellowships.

\section{References}

1. Wasielewski M R 1992 Chem. Rev. 92435

2. Connolly J S and Bolton J R 1998 In Photoinduced electron transfer (eds) M A Fox and M Chanon M (Amsterdam: Elsevier) part D, p. 303

3. Barbara P F, Meyer T J and Ratner M A $1996 \mathrm{~J}$. Phys. Chem. 10013148

4. Pullerits T and Sundstrom V 1996 Acc. Chem. Res. 29381

5. Guldi D M 2002 Chem. Soc. Rev. 3122.

6. Gust D and Moore T 2000 The porphyrin handbook (eds) K M Kadish, K M Smith and R Guilard (San Diego: Academic Press)

7. Choi M-S, Aida T, Yamazaki T and Yamazaki I 2002 Chem. Eur. J. 82667

8. Tomizaki K-Y, Loewe R S, Kirmaier C, Schwartz J K, Retsek J L, Bocian D F and Lindsey J S $2002 \mathrm{~J}$. Org. Chem. 676519

9. Ward M D 1997 Chem. Soc. Rev. 365

10. Hayashi T and Ogoshi H 1997 Chem. Soc. Rev. 355

11. Piotrowiak P 1999 Chem. Soc. Rev. 28143

12. Rajesh C S, Capitosti G J, Cramer S J and Modarelli D A 2001 J. Phys. Chem. B105 10175

13. Capitosti G J, Cramer S J, Rajesh C S and Modarelli D A 2001 Org. Lett. 31645

14. D'Souza F and Deviprasad G R $2001 \mathrm{~J}$. Org. Chem. 664601

15. Kuruda Y, Ito M, Sera T and Ogoshi H 1993 J. Am. Chem. Soc. 1157003

16. Kamioka K, Cormier R A, Lutton T W and Connolly J S 1992 J. Am. Chem. Soc. 1144414

17. Hamaoue K, Nakayama T, Nanshow H, Ushida K, Naruta Y, Kodo T and Maruyama K 1991 Chem. Phys. Lett. 187409

18. Li L, Shen S, Yu Q, Zhou Q and Xu H 1991 J. Chem. Soc., Chem. Commun. 619

19. Cormier R A, Posey M R, Bell W L, Fonda H N and Connolly J S 1989 Tetrahedron 454831

20. Kang Y K, Rubstov I V, Iovine P M, Chen J and Therien M J 2002 J. Am. Chem. Soc. 1248275

21. Sen A and Krishnan V 1999 J. Photochem. Photobiol. A123 77

22. Perrin D D, Armarego W L F and Perrin D R 1986 Purification of laboratory chemicals (Oxford: Pergamon)

23. Hombrecher H K and Ludtke K 1993 Tetrahedron 49 9489

24. Fuhrhop J-H, Smith K M 1975 Porphyrins and metalloporphyrins (ed.) K M Smith (Amsterdam: Elsevier) p. 179

25. Gardner M, Guerin A J, Hunter C A, Michelsen U and Rotger C 1999 New J. Chem. 309

26. Vogel 1989 Textbook of practical organic chemistry (London: ELBS) p. 1000

27. Quimby D J and Longo F R 1975 J. Am. Chem. Soc. 195111 
28. Harriman A and Davila J 1989 Tetrahedron 454737

29. Maiya B G, Doraisamy S, Periasamy N and Venkataraman B 1994 J. Photochem. Photobiol. A81 139

30. Sirish M and Maiya B G 1994 J. Photochem. Photobiol. A77 189

31. Sirish M, Kache R and Maiya B G 1996 J. Photochem. Photobiol. A93 129

32. Sirish M and Maiya B G 1995 J. Photochem. Photobiol. A88 127

33. Kumar A A, Giribabu L, Reddy D R and Maiya B G 2001 Inorg. Chem. 406757

34. Reddy D R and Maiya B G 2002 J. Porphyrins Phthalocyanines 61

35. Prashanth P K and Maiya B G 2003 New J. Chem. 27 619
36. Prashanth P K and Maiya B G 2003 Indian J. Chem. A42 2198

37. Senge M O, Soeck M, Wiehe A, Dieks H, Aguirre S and Kurreck H 1999 Photochem. Photobiol. 70206

38. Hayashi T, Takimura T, Hitomi Y, Ohara T and Ogoshi H 1995 J. Chem. Soc., Chem. Commn. 545.

39. Abraham R J, Bedford G R, McNeillie D and Wright B 1980 Org. Magn. Reson. 14418

40. Zhang J, Sun H-R, Yang G-Y, Wen K, Yu L-X and Cao X-Z 1998 Electrochem. Acta 432693.

41. Subramanian J 1975 In Porphyrins and metalloporphyrins (ed.) K M Smith (Amsterdam: Elsevier) p. 562

42. Joran A D, Leland B A, Felker P M, Zewail H J, Hopfield J and Dervan P B 1987 Nature (London) $\mathbf{3 2 7} 508$ 